\title{
Predictors of pathologic complete response after preoperative concurrent chemoradiotherapy of rectal cancer: a single center experience
}

\author{
Euncheol Choi, MD¹, Jin Hee Kim, MD, PhD², Ok Bae Kim, MD, PhD², Mi Young Kim, MD², \\ Young Ki Oh, PhD², Sung Gyu Baek, MD, PhD ${ }^{3}$
}

${ }^{1}$ Proton Therapy Center, National Cancer Center, Goyang; Departments of ${ }^{2}$ Radiation Oncology and ${ }^{3}$ Colorectal Surgery, Dongsan Medical Center, Keimyung University School of Medicine, Daegu, Korea

Purpose: To identify possible predictors of pathologic complete response (PCR) of rectal cancer after preoperative concurrent chemoradiotherapy (CCRT).

Materials and Methods: We conducted a retrospective review of 53 patients with rectal cancer who underwent preoperative CCRT followed by radical surgery at a single center between January 2007 and December 2012. The median radiotherapy dose to the pelvis was $54.0 \mathrm{~Gy}$ (range, 45.0 to $63.0 \mathrm{~Gy}$ ). Five-fluorouracil-based chemotherapy was administered via continuous infusion with leucovorin.

Results: The $\mathrm{pCR}$ rate was $20.8 \%$. The downstaging rate was $66 \%$. In univariate analyses, poor and undifferentiated tumors $(p=$ $0.020)$ and an interval of $\geq 7$ weeks from finishing CCRT to surgery $(p=0.040)$ were significantly associated with $p C R$, while female gender $(p=0.070)$, initial carcinoembryonic antigen concentration of $<5.0 \mathrm{ng} / \mathrm{dL}(p=0.100)$, and clinical stage T2 $(p=0.100)$ were marginally significant factors. In multivariate analysis, an interval of $\geq 7$ weeks from finishing CCRT to surgery (odds ratio, 0.139; $95 \%$ confidence interval, 0.022 to $0.877 ; p=0.036$ ) was significantly associated with $p C R$, while stage T2 (odds ratio, 5.363; 95\% confidence interval, 0.963 to $29.877 ; p=0.055$ ) was a marginally significant risk factor.

Conclusion: We suggest that the interval from finishing CCRT to surgery is a predictor of pCR after preoperative CCRT in patients with rectal cancer. Stage T2 cancer may also be an important predictive factor. We hope to perform a robust study by collecting data during treatment to obtain more advanced results.

Keywords: Rectum, Rectal neoplasms, Chemoradiotherapy, Stage, Interval

\section{Introduction}

According to the annual report of cancer statistics published in 2010, colorectal cancer is the third most common malignancy in Korea, accounting for $12.8 \%$ of all cancers. The incidence of colorectal cancer has gradually increased since the start of cancer registration [1]. For locally advanced rectal cancer, the initial treatment involves preoperative concurrent chemoradiotherapy (CCRT). A few weeks after completing CCRT, total mesorectal excision is performed in accordance

Received 10 December 2015, Revised 29 March 2016, Accepted 10 May 2016.

Correspondence: Jin Hee Kim, MD, PhD, Department of Radiation Oncology, Dongsan Medical Center, Keimyung University School of Medicine, 56 Dalseong-ro, Jung-gu, Daegu 41931, Korea. Tel: +82-53-250-7665, Fax: +82-53-250-7984, E-mail: jhkim@dsmc.or.kr

(c) This is an Open Access article distributed under the terms of the Creative Commons Attribution Non-Commercial License (http://creativecommons.org/ licenses/by-nc/4.0/) which permits unrestricted non-commercial use, distribution, and reproduction in any medium, provided the original work is properly cited.

www.e-roj.org 
with recent treatment guidelines [2-6].

In various studies of rectal cancer, the predictive factors for survival included tumor stage, lymphovascular invasion, histopathologic grade, circumferential tumor, deep ulceration, fixation, and tumor regression grade after CCRT [7-12].

Tumor regression grade reflects the response of a tumor to treatment. Most grading systems range from complete response $(\mathrm{CR})$ to disease progression, with defined endpoints of $C R$, partial response, stable disease, and progressive disease. Patients with CR had better 5-year disease-free survival than patients with partial response or stable disease [11]. Maas et al. [13] performed a meta-analysis of the long-term outcomes of patients with pathologic complete response (pCR) after preoperative CCRT for rectal cancer. Patients with $\mathrm{pCR}$ had better disease-free survival and overall survival than patients without pCR.

In several studies, pCR after CCRT was an important predictive factor for survival. The ability to predict the likelihood of pCR from clinical factors could be helpful in clinical practice. Therefore, this retrospective study was designed to identify possible predictive factors for pCR after preoperative CCRT for rectal cancer in patients at a single center.

\section{Materials and Methods}

\section{Patient selection}

Between January 2007 and December 2012, 56 patients with rectal cancer were referred for preoperative CCRT at Keimyung University Dongsan Medical Center. All patients underwent preoperative CCRT followed by surgery. Most patients underwent preoperative imaging, including computed tomography $(\mathrm{CT})$, magnetic resonance imaging (MRI), and colonoscopy. Blood carcinoembryonic antigen (CEA) and hemoglobin $(\mathrm{Hb})$ tests were performed initially. Of the 56 patients, the pathologic response could not be determined in 2 patients because of limitations associated with the surgical methods, including local excision and open and closure. In 1 patient, the initial staging was incomplete. Therefore, 53 patients were analyzed in this study.

\section{Treatments}

External beam radiotherapy was usually performed with the patient in the prone position using a belly board. Threedimensional conformal technique was used in all patients. The patients received a median total dose of $54.0 \mathrm{~Gy}$ (range, 45.0 to $63.0 \mathrm{~Gy})$, at a once-daily dose of $1.8 \mathrm{~Gy}$. The total dose applied was chosen by the radiation oncologist. Five-fluorouracilbased chemotherapy was administered via continuous infusion with leucovorin. The first cycle of chemotherapy was administered from day 1 to day 5 , and the second cycle of chemotherapy was administered from day 29 to day 33 . The surgical procedure was based on Miles' operation, and lower anterior resection or anterior resection was performed 6-8 weeks after completing CCRT. The type of surgery was selected by the colorectal surgeon. In one exception, local excision was performed.

\section{Clinical variables and definitions}

This study analyzed various factors, including age, gender, performance status, smoking, differentiation, distance from the anal verge (AV), tumor size, circumferential tumor, initial CEA concentration, initial $\mathrm{Hb}$ concentration, T stage, lymph node involvement, total radiotherapy dose, post-CCRT colonoscopy, post-CCRT CEA concentration, and the interval from CCRT to surgery.

The cut-off CEA concentration was $5.0 \mathrm{ng} / \mathrm{dL}$, which in our laboratoryis the CEA concentration considered abnormal. The cut-off value for $\mathrm{Hb}$ concentration was $10.0 \mathrm{~g} / \mathrm{dL}$. The T stage was determined by the CT or MRI findings. The improvements at post-CCRT colonoscopy were based on the gross findings observed during colonoscopy. Pathologic examination was performed by 1 pathologist specialized in gastrointestinal (GI) anatomy. pCR was defined as no viable tumor cells in the primary lesion or lymph nodes in postoperative tissue specimens. Partial response was defined as the presence of residual tumor cells and the pathologic report showing an improvement in the $\mathrm{T}$ or $\mathrm{N}$ stages after preoperative CCRT. Stable disease was defined as no change in the clinical or pathologic stages. Progression was defined as worsening of the clinical or pathologic stages.

\section{Statistics}

Univariate analyses were performed using $\chi^{2}$ tests or Fisher exact test to evaluate the associations between clinical variables and the $\mathrm{pCR}$ rate. Multivariate logistic regression analysis was performed to evaluate the association between potential predictors identified in univariate analysis with the $p C R$ rate. The $p$-values of $<0.05$ were considered statistically significant. Statistical analyses were performed using IBM SPSS ver. 20.0 (IBM, Armonk, NY, USA). 


\section{Results}

The median age was 60 years (range, 32 to 78 years) and $69.8 \%$ of patients were males. All patients had good performance with a performance status of 0 or 1 . Most of the patients had moderately differentiated histology (92.4\%). The median initial CEA concentration was $4.14 \mathrm{ng} / \mathrm{dL}$ (range, 0.75 to $93.59 \mathrm{ng} / \mathrm{dL}$ ). The median initial $\mathrm{Hb}$ concentration was 12.40 $\mathrm{g} / \mathrm{dL}$ (range, 8.00 to $15.60 \mathrm{~g} / \mathrm{dL}$ ). Of the 53 patients, the T stage was T2 in 12 patients, T3 in 35 patients, and T4 in 6 patients. Patients with T2 stage had large tumors and tumors close to the $A V$, which required anal-sparing procedures. Thirty-seven patients had lymph node involvement. Most of the patients were received a radiotherapy dose of $\geq 50.4 \mathrm{~Gy}$ (94.3\%). The median post-CCRT CEA concentration was $2.11 \mathrm{ng} / \mathrm{dL}$ (range, 0.28 to $11.90 \mathrm{ng} / \mathrm{dL}$ ). The other patient characteristics are listed in Table 1.

All of the patients underwent surgery, comprising local excision in 1 patient, Miles' surgery in 11 patients, and lower anterior resection and anterior resection in 41 patients. Most of the patients underwent surgery between 6 and 8 weeks after CCRT. The postoperative pCR rate was 20.8\% (11/53) and the downstaging rate was $66.0 \%(35 / 53)$.

Tables 2 and 3 summarize the univariate and multivariate analyses of predictive factors for $\mathrm{PCR}$. In univariate analyses, patients with poorly differentiated or undifferentiated histology had a higher pCR rate than patients with well or moderately differentiated histology $(75.0 \%$ vs. $16.3 \%$; $p=$ 0.02). An interval from finishing CCRT to surgery of $\geq 7$ weeks was also a significant predictive factor $(33.3 \%$ vs. $7.7 \% ; p=$ 0.04). The $p C R$ rate was higher in females than in males. An initial CEA concentration of $<5.0 \mathrm{ng} / \mathrm{dL}$ was associated with a higher $p C R$ rate. The $p C R$ rate was also higher in patients with $\mathrm{T} 2$ stage cancer than in patients with $\mathrm{T} 3$ or $\mathrm{T} 4$ stage cancers. The differences in $\mathrm{pCR}$ rates among genders, initial CEA concentrations, and T stages were marginally significant. Age, performance status, smoking, distance from the $A V$, lesion size, circumferential tumor, initial Hb concentration, lymph nodes involvement, total radiotherapy dose, post-CCRT colonoscopy findings, and post-CCRT CEA concentrations were not significantly associated with $\mathrm{PCR}$ in univariate analyses.

Variables with a $p$-value of $<0.100$ were included in the multivariate analysis. The interval from finishing CCRT to surgery (odds ratio [OR], 0.139; 95\% confidence interval [CI], 0.022 to $0.877 ; p=0.036$ ) was significantly and independently associated with $\mathrm{pCR}$. The association between T stage and $\mathrm{pCR}$ was marginally significant $(O R, 5.363 ; 95 \% \mathrm{Cl}, 0.963$ to 29.877 ;
Table 1. Patient characteristics

\begin{tabular}{|c|c|}
\hline Characteristic & Value \\
\hline Age (yr) & $60(32-78)$ \\
\hline$\leq 60$ & $28(52.8)$ \\
\hline$>60$ & $25(47.2)$ \\
\hline \multicolumn{2}{|l|}{ Gender } \\
\hline Male & $37(69.8)$ \\
\hline Female & $16(30.2)$ \\
\hline \multicolumn{2}{|l|}{ Performance status } \\
\hline ECOG 0 & $25(47.2)$ \\
\hline ECOG 1 & $28(52.8)$ \\
\hline \multicolumn{2}{|l|}{ Smoking } \\
\hline Non-smoker & $25(47.2)$ \\
\hline Smoker & $28(52.8)$ \\
\hline \multicolumn{2}{|l|}{ Differentiation } \\
\hline Well and moderate differentiated & $49(92.4)$ \\
\hline Poorly and undifferentiated & $4(7.6)$ \\
\hline Distance from anal verge $(\mathrm{cm})$ & $7(0-15)$ \\
\hline$\leq 6$ & $27(50.9)$ \\
\hline$>6$ & $26(49.1)$ \\
\hline Mass size $(\mathrm{cm})$ & $5(3-12)$ \\
\hline$\leq 5$ & $17(32.1)$ \\
\hline$>5$ & $36(67.9)$ \\
\hline Circumference (\%) & $100(25-100)$ \\
\hline$<100$ & $25(47.2)$ \\
\hline 100 & $28(52.8)$ \\
\hline Initial CEA level (ng/dL) & $4.14(0.75-93.59)$ \\
\hline$\leq 5$ & $30(56.6)$ \\
\hline$>5$ & $22(41.5)$ \\
\hline Unknown & $1(1.9)$ \\
\hline \multicolumn{2}{|l|}{ Elevation of CEA level } \\
\hline Elevation & $27(50.9)$ \\
\hline No elevation & $25(47.2)$ \\
\hline Unknown & $1(1.9)$ \\
\hline Initial Hb level (g/mL) & $12.4(8.0-15.6)$ \\
\hline$<10$ & $7(13.2)$ \\
\hline$\geq 10$ & $46(86.8)$ \\
\hline \multicolumn{2}{|l|}{ Clinical T stage } \\
\hline $\mathrm{T} 2$ & $12(22.6)$ \\
\hline $\mathrm{T} 3, \mathrm{~T} 4$ & $41(77.4)$ \\
\hline \multicolumn{2}{|l|}{ Lymph node involvement } \\
\hline$N(-)$ & $16(30.2)$ \\
\hline $\mathrm{N}(+)$ & $37(69.8)$ \\
\hline Total dose of radiotherapy (Gy) & $54.0(45.0-63.0)$ \\
\hline$<50.4$ & $3(5.7)$ \\
\hline$\geq 50.4$ & $50(94.3)$ \\
\hline \multicolumn{2}{|l|}{ Post CCRT colonoscopy } \\
\hline Improved & $37(69.8)$ \\
\hline Not improved & $8(15.1)$ \\
\hline Unknown & $8(15.1)$ \\
\hline Post-CCRT CEA (ng/dL) & $2.11(0.28-11.90)$ \\
\hline$\leq 5$ & $45(84.9)$ \\
\hline$>5$ & $6(11.3)$ \\
\hline Unknown & $2(3.8)$ \\
\hline
\end{tabular}

Continued on the next page. 
Table 1. Continued

\begin{tabular}{cc}
\hline \multicolumn{1}{c}{ Characteristic } & Value \\
\hline Interval from CCRT to operation (wk) & $7(4-15)$ \\
$<7$ & $26(49.1)$ \\
$\geq 7$ & $27(50.9)$ \\
\hline
\end{tabular}

Values are presented as median (range) or number (\%). ECOG, Eastern Cooperative Oncology Group; CEA, carcinoembryonic antigen; $\mathrm{Hb}$, hemoglobin; $\mathrm{CCRT}$, concurrent chemoradiotherapy. $p=0.055)$. Gender and initial CEA were not significantly associated with $\mathrm{pCR}$ in the multivariate analysis.

Regarding complications after CCRT, GI complications were the most common. Twenty-six patients had grade $1 \mathrm{GI}$ complications. Ten patients had grade $2 \mathrm{Gl}$ complications, which required pharmacotherapy. Eleven patients had grade 1 genitourinary (GU) complications. Three patients had grade 2 GU complications. There were no grade 3 or 4 complications. Most of the patients tolerated their surgeries. Two patients had grade $2 \mathrm{Gl}$ complications, such as bowel obstruction, that required supportive management. One patient had a grade 1

Table 2. Univariate analysis of predictors for pathologic complete response

\begin{tabular}{|c|c|c|c|c|}
\hline Characteristic & Total $(n=53)$ & $\mathrm{pCR}(\mathrm{n}=11)$ & No pCR $(n=42)$ & $p$-value \\
\hline Age (yr) & & & & 1.00 \\
\hline$\leq 60$ & $28(100)$ & $6(21.4)$ & $22(78.6)$ & \\
\hline$>60$ & $25(100)$ & $5(20.0)$ & $20(80.0)$ & \\
\hline Gender & & & & 0.07 \\
\hline Male & $37(100)$ & $5(13.5)$ & $32(86.5)$ & \\
\hline Female & $16(100)$ & $6(37.5)$ & $10(62.5)$ & \\
\hline Performance status & & & & 0.18 \\
\hline ECOG 0 & $25(100)$ & $3(12.0)$ & $22(88.0)$ & \\
\hline ECOG 1 & $28(100)$ & $8(28.6)$ & $20(71.4)$ & \\
\hline Smoking & & & & 0.74 \\
\hline Non-smoker & $25(100)$ & $6(24.0)$ & $19(76.0)$ & \\
\hline Smoker & $28(100)$ & $5(17.9)$ & $23(82.1)$ & \\
\hline Differentiation & & & & 0.02 \\
\hline WD and MD & $49(100)$ & $8(16.3)$ & $41(83.7)$ & \\
\hline PD and UD & $4(100)$ & $3(75.0)$ & $1(25.0)$ & \\
\hline Distan ce from AV (cm) & & & & 0.33 \\
\hline$\leq 6$ & $26(100)$ & $4(14.8)$ & $23(85.2)$ & \\
\hline$>6$ & $27(100)$ & $7(26.9)$ & $19(73.1)$ & \\
\hline Mass size (cm) & & & & 0.18 \\
\hline$\leq 5$ & $17(100)$ & $7(20.0)$ & $28(80.0)$ & \\
\hline$>5$ & $36(100)$ & $4(22.2)$ & $14(77.8)$ & \\
\hline Circumference (\%) & & & & 1.00 \\
\hline$<100$ & $25(100)$ & $6(24.0)$ & $19(76.0)$ & \\
\hline 100 & $28(100)$ & $5(17.9)$ & $23(82.1)$ & \\
\hline Initial CEA level (ng/dL) & & & & 0.10 \\
\hline$\leq 5$ & $30(100)$ & $7(23.3)$ & $23(76.7)$ & \\
\hline$>5$ & $22(100)$ & $3(13.6)$ & $19(86.4)$ & \\
\hline Unknown & $1(100)$ & $1(100)$ & $0(0)$ & \\
\hline Elevation of CEA level & & & & 0.12 \\
\hline Elevation & $27(100)$ & $4(16.0)$ & $21(84.0)$ & \\
\hline No elevation & $25(100)$ & $6(22.2)$ & $21(77.8)$ & \\
\hline Unknown & $1(100)$ & $1(100)$ & $0(0)$ & \\
\hline Initial Hb level (g/mL) & & & & 1.00 \\
\hline$<10$ & $7(100)$ & $1(14.3)$ & $6(85.7)$ & \\
\hline$\geq 10$ & $46(100)$ & $10(21.7)$ & $36(78.3)$ & \\
\hline
\end{tabular}

Continued on the next page. 
Table 2. Continued

\begin{tabular}{|c|c|c|c|c|}
\hline Characteristic & Total $(n=53)$ & $\mathrm{pCR}(\mathrm{n}=11)$ & No $p C R(n=42)$ & $p$-value \\
\hline Clinical T stage & & & & 0.10 \\
\hline $\mathrm{T} 2$ & $12(100)$ & $5(41.7)$ & $7(58.3)$ & \\
\hline $\mathrm{T} 3, \mathrm{~T} 4$ & $41(100)$ & $6(14.6)$ & $35(85.4)$ & \\
\hline Lymph node involvement & & & & 0.72 \\
\hline$N(-)$ & $16(100)$ & $4(25.0)$ & $12(75.0)$ & \\
\hline $\mathrm{N}(+)$ & $37(100)$ & $7(18.9)$ & $30(81.1)$ & \\
\hline Total dose of radiotherapy (Gy) & & & & 0.11 \\
\hline$<50.4$ & $3(100)$ & $2(66.7)$ & $1(33.3)$ & \\
\hline$\geq 50.4$ & $50(100)$ & $9(18.0)$ & $41(82.0)$ & \\
\hline Post-CCRT colonoscopy & & & & 0.62 \\
\hline Improved & $37(100)$ & $9(24.3)$ & $28(75.7)$ & \\
\hline Not improved & $8(100)$ & $1(12.5)$ & $7(87.5)$ & \\
\hline Unknown & $8(100)$ & $1(12.5)$ & $7(87.5)$ & \\
\hline Post-CCRT CEA (ng/dL) & & & & 0.26 \\
\hline$\leq 5$ & $45(100)$ & $10(22.2)$ & $35(77.8)$ & \\
\hline$>5$ & $6(100)$ & $0(0)$ & $6(100)$ & \\
\hline Unknown & $2(100)$ & $1(50.0)$ & $1(50.0)$ & \\
\hline Interval from CCRT to operation (wk) & & & & 0.04 \\
\hline$<7$ & $26(100)$ & $2(7.7)$ & $24(92.3)$ & \\
\hline$\geq 7$ & $27(100)$ & $9(33.3)$ & $18(66.7)$ & \\
\hline
\end{tabular}

Values are presented as number (\%).

pCR, pathologic complete response; ECOG, Eastern Cooperative Oncology Group; WD and MD, well and moderate differentiated; PD and $U D$, poorly and undifferentiated; $A V$, anal verge; CEA, carcinoembryonic antigen; $\mathrm{Hb}$, hemoglobin; CCRT, concurrent chemoradiotherapy.

Table 3. Multivariate analysis of predictors for pathologic complete response

\begin{tabular}{lccc}
\hline \multicolumn{1}{c}{ Characteristic } & OR & $95 \% \mathrm{Cl}$ & p-value \\
\hline $\begin{array}{l}\text { Gender (male vs. female) } \\
\text { Initial CEA level }\end{array}$ & 0.308 & $0.054-1.752$ & 0.184 \\
$\quad$ ( $\leq 5 \mathrm{vs} .>5 \mathrm{ng} / \mathrm{dL})$ & 0.970 & $0.180-5.233$ & 0.972 \\
$\begin{array}{l}\text { Clinical T stage } \\
\text { (T2 vs. T3, T4) }\end{array}$ & 5.363 & $0.963-29.877$ & 0.055 \\
$\begin{array}{l}\text { Interval from CCRT to } \\
\text { operation ( }<7 \text { vs. } \geq 7 \text { wk) }\end{array}$ & 0.139 & $0.022-0.877$ & 0.036 \\
\hline
\end{tabular}

$O R$, odds ratio; $\mathrm{Cl}$, confidence interval; $C E A$, carcinoembryonic antigen; CCRT, concurrent chemoradiotherapy.

GU complication. There were no grade 3 or 4 complications after surgery.

\section{Discussion and Conclusion}

Several retrospective studies [14-24] have examined the predictive factors for $\mathrm{pCR}$ in patients with rectal cancer. These studies suggested that several pretreatment laboratory findings (e.g., Hb, serum albumin, and CEA concentrations, and the neutrophil to lymphocyte ratio) and the posttreatment
CEA concentration were potential predictive factors. Biological markers such as lower epidermal growth factor receptor expression, higher thymidylate synthase expression, high Ki67 level, and wild-type p53 status were associated with pCR. Several imaging modalities were used to predict $\mathrm{PCR}$, including diffusion-weighted MRI and positron emission tomography/CT. The change in tumor volume during or after CCRT, the initial apparent diffusion coefficient (ADC), and the change in ADC during or after CCRT were associated with $\mathrm{pCR}$. The maximum standardized uptake value (SUV) after treatment and the decrease in SUV after treatment were also predictive factors in some studies. Other factors such as the circumferential extent, macroscopic ulceration, and the distance from the AV were also associated with pCR [14-24].

In our univariate analyses, we found that the $\mathrm{pCR}$ rate was higher in patients with worse differentiation, T2 stage cancer, and a longer interval from finishing CCRT to surgery. An initial CEA concentration of $<5 \mathrm{ng} / \mathrm{dL}$ was also associated with $\mathrm{pCR}$. The pretreatment serum albumin concentration, neutrophil to lymphocyte ratio, and other biomarkers were not assessed in this study because these factors were not initially included in our institution's protocol. In related studies, Das et al. [21] reported that a pretreatment CEA concentration of 
$<2.5 \mathrm{ng} / \mathrm{dL}(\mathrm{p}=0.010)$ was associated with $\mathrm{pCR}$ in univariate analysis. The interval from finishing CCRT to surgery ( $p=$ 0.006) was reported to be a predictive factor for $\mathrm{PCR}$ in the study of Wolthuis et al. [22]. Huh et al. [23] reported that the pretreatment CEA concentration $(<5 \mathrm{ng} / \mathrm{mL}$ vs. $\geq 5 \mathrm{ng} / \mathrm{mL} ; O R$, $2.660 ; 95 \% \mathrm{Cl}_{1} 1.380$ to $5.120 ; p=0.010$ ) was a significant predictive factor in their multivariate analysis. Better differentiation ( $p=0.009)$ and lower $T$ stage $(p=0.001)$ were statistically significant in univariate analyses [23]. Furthermore, Restivo et al. [24] reported that lower pretreatment CEA concentrations $(p<0.001)$ and better differentiation ( $p=$ 0.010 ) were statistically significant in univariate analysis, and CEA $<5.0 \mathrm{ng} / \mathrm{dL}$ was independently associated with $\mathrm{pCR}$ in the multivariate analysis $(\mathrm{OR}, 9.320 ; 95 \% \mathrm{Cl}, 2.160$ to 40.190; $p=$ 0.030) [24].

There are some differences between the results of our study and those of other studies. The first difference relates to the influence of differentiation. In our study, patients with worse differentiation had a higher $\mathrm{PCR}$ rate, whereas patients with better differentiation had a higher $\mathrm{pCR}$ rate in earlier studies $[23,24]$. In our study, only 4 patients had poorly differentiated or undifferentiated histology, which probably introduced significant bias. Therefore, we think these results are unreliable and differentiation was excluded from the multivariate analysis. The second difference is the staging work-up used in our study. The standard diagnostic tools currently used for T staging are MRI or endorectal ultrasonography. In our study, CT or MRI were used for T staging. Although CT is a nonstandard diagnostic tool, staging was included in the CT reports prepared by the radiologist. The stage mentioned in these reports could differ from the stage determined using standardized methods. The third difference is the cut-off values used in each study. We estimated the predictive role of laboratory variables by applying various cut-off values. The cut-off values were chosen after considering the values used in other studies. We initially used cut-off values of 10, 11, and $12 \mathrm{~g} / \mathrm{mL}$ for $\mathrm{Hb}$ concentrations and 2.5, 4, and $5 \mathrm{ng} / \mathrm{dL}$ for CEA concentrations. However, none of these cut-off values was significantly associated with $\mathrm{pCR}$ in univariate analyses, with the exception of an initial CEA concentration of $<5 \mathrm{ng} / \mathrm{dL}$, which showed an association with $\mathrm{pCR}$, albeit at a marginal significance level.

From a clinical perspective, although T2 stage cancer is not an indication for CCRT in the National Comprehensive Cancer Networkguidelines [2-6], some patients with T2 stage cancers undergo CCRT. CCRT was associated with a high pCR rate in some studies, including in our study. Therefore,
CCRT may be suitable for selected patients who require analsparing procedures. A major factor in selecting CCRT for T2 stage cancer is precise $T$ staging using appropriate imaging modalities, and this attempts to predict pCR. A long interval between finishing CCRT and surgery was a significant predictive factor in the multivariate analysis in our study. Thus, the timing of surgery is important. Some studies reported the interval between CCRT and surgery $[25,26]$, in which the interval ranged from 4 to 8 weeks. Based on the findings of these studies, all patients could undergo complete resection without an increased rate of postoperative complications. According to these results, an interval of 4-8 weeks from finishing CCRT to performing surgery seems to be suitable and did not promote complications related to CCRT. Most of the patients in our study underwent surgery between 6 and 8 weeks after CCRT. Five patients underwent surgery $>8$ weeks after CCRT, and all 5 patients had T3 stage cancer. The T stage was not significantly different between patients with a longer vs. shorter interval. There were no postoperative complications in these 5 patients with $\mathrm{T} 3$ stage cancer. The low rates of $\mathrm{Gl}$ or GU complications after surgery were possibly due to the study design. Because this was a retrospective study, the medical records for postoperative complications were written by the surgeon, not by an investigator according to a defined procedure. Therefore, some patients may have experienced some postoperative complications, which were not recorded by the surgeon.

In conclusion, we investigated the potential predictive factors for $\mathrm{pCR}$ of rectal cancer in 53 patients who underwent CCRT followed by surgery. The interval from finishing CCRT to surgery was an independent predictive factor for $\mathrm{PCR}$ in this cohort of patients. Although the T stage was only marginally significant in the multivariate analysis, this potential association is clinically relevant. Some limitations of this study include the small number of patients and its retrospective design. In the future, a well-designed prospective study is needed to identify other potential predictive factors, including unknown biological markers, for pCR after preoperative CCRT and surgery in patients with rectal cancer.

\section{Conflict of Interest}

No potential conflict of interest relevant to this article was reported. 


\section{References}

1. Korea Central Cancer Registry. Annual report of cancer statistics in Korea in 2010. Goyang: Korea Central Cancer Registry; 2012.

2. Sauer $R_{1}$ Becker $H_{1}$ Hohenberger $W_{1}$ et al. Preoperative versus postoperative chemoradiotherapy for rectal cancer. N Engl J Med 2004:351:1731-40.

3. Gerard JP, Conroy $T$, Bonnetain $F$, et al. Preoperative radiotherapy with or without concurrent fluorouracil and leucovorin in T3-4 rectal cancers: results of FFCD 9203. J Clin Oncol 2006;24:4620-5.

4. Bosset JF, Collette L, Calais $G$, et al. Chemotherapy with preoperative radiotherapy in rectal cancer. N Engl J Med 2006;355:1114-23.

5. Roh MS, Colangelo LH, O'Connell MJ, et al. Preoperative multimodality therapy improves disease-free survival in patients with carcinoma of the rectum: NSABP R-03. J Clin Oncol 2009;27:5124-30.

6. Park JH, Yoon SM, Yu CS, Kim JH, Kim TW, Kim JC. Randomized phase 3 trial comparing preoperative and postoperative chemoradiotherapy with capecitabine for locally advanced rectal cancer. Cancer 2011;117:3703-12.

7. Sasaki O, Atkin WS, Jass JR. Mucinous carcinoma of the rectum. Histopathology 1987;11:259-72.

8. Crucitti F, Sofo L, Doglietto GB, et al. Predictive factors in colorectal cancer: current status and new trends. J Surg Oncol Suppl 1991;2:76-82.

9. Kapiteijn E, Marijnen CA, Nagtegaal ID, et al. Preoperative radiotherapy combined with total mesorectal excision for resectable rectal cancer. N Engl J Med 2001;345:638-46.

10. Gunderson LL, Sargent DJ, Tepper JE, et al. Impact of T and N stage and treatment on survival and relapse in adjuvant rectal cancer: a pooled analysis. J Clin Oncol 2004;22:1785-96.

11. Rodel $C$, Martus P, Papadoupolos T, et al. Predictive significance of tumor regression after preoperative chemoradiotherapy for rectal cancer. J Clin Oncol 2005;23:8688-96.

12. Quirke P, Steele R, Monson J, et al. Effect of the plane of surgery achieved on local recurrence in patients with operable rectal cancer: a prospective study using data from the MRC CR07 and NCIC-CTG C016 randomised clinical trial. Lancet 2009:373:821-8

13. Maas $M$, Nelemans PJ, Valentini $V$, et al. Long-term outcome in patients with a pathological complete response after chemoradiation for rectal cancer: a pooled analysis of individual patient data. Lancet Oncol 2010;11:835-44.

14. Khan AA, Klonizakis M, Shabaan A, Glynne-Jones R. Association between pretreatment haemoglobin levels and morphometric characteristics of the tumour, response to neoadjuvant treatment and long-term outcomes in patients with locally advanced rectal cancers. Colorectal Dis 2013;15:1232-7.

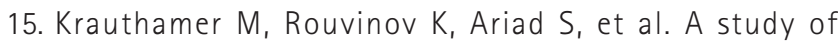
inflammation-based predictors of tumor response to neoadjuvant chemoradiotherapy for locally advanced rectal cancer. Oncology 2013;85:27-32

16. Carlomagno $C$, Pepe $S$, D'Armiento FP, et al. Predictive factors of complete response to neoadjuvant chemoradiotherapy in patients with rectal cancer. Oncology 2010;78:369-75.

17. Chen MB, Wu XY, Yu R, et al. P53 status as a predictive biomarker for patients receiving neoadjuvant radiationbased treatment: a meta-analysis in rectal cancer. PLoS One 2012;7:e45388.

18. Lambrecht $M$, Vandecaveye $V$, De Keyzer $F$, et al. Value of diffusion-weighted magnetic resonance imaging for prediction and early assessment of response to neoadjuvant radiochemotherapy in rectal cancer: preliminary results. Int J Radiat Oncol Biol Phys 2012;82:863-70.

19. Shanmugan S, Arrangoiz R, Nitzkorski JR, et al. Predicting pathological response to neoadjuvant chemoradiotherapy in locally advanced rectal cancer using 18FDG-PET/CT. Ann Surg Oncol 2012;19:2178-85.

20. Kim JW, Kim HC, Park JW, et al. Predictive value of (18)FDG PET-CT for tumour response in patients with locally advanced rectal cancer treated by preoperative chemoradiotherapy. Int $J$ Colorectal Dis 2013;28:1217-24.

21. Das P, Skibber JM, Rodriguez-Bigas MA, et al. Predictors of tumor response and downstaging in patients who receive preoperative chemoradiation for rectal cancer. Cancer 2007;109:1750-5.

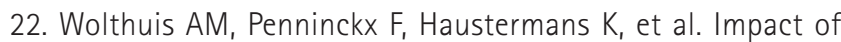
interval between neoadjuvant chemoradiotherapy and TME for locally advanced rectal cancer on pathologic response and oncologic outcome. Ann Surg Oncol 2012;19:2833-41.

23. Huh JW, Kim HR, Kim YJ. Clinical prediction of pathological complete response after preoperative chemoradiotherapy for rectal cancer. Dis Colon Rectum 2013;56:698-703.

24. Restivo A, Zorcolo L, Cocco IM, et al. Elevated CEA levels and low distance of the tumor from the anal verge are predictors of incomplete response to chemoradiation in patients with rectal cancer. Ann Surg Oncol 2013;20:864-71.

25. Pettersson $D$, Cedermark $B$, Holm $T$, et al. Interim analysis of the Stockholm III trial of preoperative radiotherapy regimens for rectal cancer. Br J Surg 2010;97:580-7.

26. Latkauskas T, Pauzas H, Gineikiene I, et al. Initial results of a randomized controlled trial comparing clinical and pathological downstaging of rectal cancer after preoperative short-course radiotherapy or long-term chemoradiotherapy both with delayed surgery. Colorectal Dis 2012;14:294-8. 